\title{
Real Time 3D echocardiography (RT3D) for assessment of ventricular and vascular function in hypertensive and heart failure patients
}

\author{
Maria Chiara Scali ${ }^{1,4^{*}}$, Massimiliano Basso ${ }^{2}$, Alfredo Gandolfo ${ }^{2}$, Tonino Bombardini ${ }^{3}$, Paolo Bellotti ${ }^{2}$ and Rosa Sicari ${ }^{3}$
}

\begin{abstract}
Background: Cardiac and systemic hemodynamics have been historically in the domain of invasive cardiology, but recent advances in real-time 3-Dimensional echocardiography (RT3D echo) provide a reliable measurement of ventricular volumes, allowing to measure a set of hemodynamic parameters previously difficult or impossible to obtain with standard $2 \mathrm{D}$ echo.

Aim: To assess the feasibility of a comprehensive hemodynamic study with RT-3D echo.

Methods: We enrolled 136 patients referred for routine echocardiography: 44 normal (N), 57 hypertensive (HYP), and 35 systolic heart failure patients (HF). All patients underwent standard 2D echo examination followed by RT3D echo examination, including measurement of left ventricular (LV) end-diastolic and end-systolic volumes and derived assessment of LV elastance (an index of LV contractility), arterial elastance (characterizing the distal impedance of the arterial system downstream of the aortic valve); ventricular-arterial coupling (a central determinant of net cardiovascular performance); systemic vascular resistances. Blood pressure was derived from cuff sphygmomanometer and heart rate from ECG.

Results: A complete 2D echo was performed in all 136 patients. 3D echo examination was obtained in 130 patients (feasibility $=95 \%$ ). Standard 2D echo examination was completed in $14.8 \pm 2.2 \mathrm{~min}$. Acquisition of 3D images required an average time of $5 \pm 0.9 \mathrm{~min}$ (range 3.5-7.5 min) and image analysis was completed in $10.1 \pm 2.8 \mathrm{~min}$ (range 6-12 min) per patient. Compared to $\mathrm{N}$ and HYP, HF patients showed reduced LV elastance $\left(1.7 \pm 1.5 \mathrm{mmHg} \mathrm{mL}^{-1} \mathrm{~m}^{-2}, \mathrm{p}<0.001\right.$ vs $\mathrm{N}=3.8 \pm 1.3$ and $\left.\mathrm{HYP}=3.8 \pm 1.3\right)$ and ventricular-arterial coupling $(0.6 \pm 0.5$, $p<0.01$ vs $N=1.4 \pm 0.4$ and $H Y P=1.2 \pm 0.4)$. Systemic vascular resistances were highest in HYP $(2736 \pm 720, p<.01$ vs $\mathrm{N}=1980 \pm 432$ and vs $\left.\mathrm{HF}=1855 \pm 636 \mathrm{dyne}{ }^{*} \mathrm{~s} / \mathrm{cm}^{5}\right)$. The LV elastance was related to $E F(r=0.73, p<0.01)$ and arterial pressure was moderately related to vascular elastance $(r=0.54, p<0.01)$. The ventricular-arterial coupling was unrelated to systemic vascular resistances $(r=-0.04, p$ NS).
\end{abstract}

Conclusion: RT-3D echo allows a non invasive, comprehensive assessment of cardiac and systemic hemodynamics, offering insight access to key variables - such as increased systemic vascular resistances in hypertensives and reduced ventricular-arterial coupling in heart failure patients.

Keywords: 3D Echocardiography, Ventricular Elastance.

\footnotetext{
* Correspondence: chiara_scali@yahoo.it

${ }^{1}$ Cardiologia Asl 2 Lucca, Lucca, Italy

${ }^{4} \mathrm{C} /$ o Cardiology Unit, Ospedale San Francesco, Via dei Frati, 1, 55051Barga,

Lucca, Italy

Full list of author information is available at the end of the article
} 


\section{Introduction}

LV function, ventricular volumes, and ejection fraction are routinely assessed by standard 2D echo for early detection of cardiac disease, to monitor disease progression and to assess response to treatment. Standard echocardiographic evaluation of hemodynamic parameters shows an acceptable correlation with invasive measurements in population studies. However, in the individual patient, the dispersion of values may be so wide to limit clinical applications, mostly due to intra- and inter-observer variability of volumes measurements [1]. RT-3D improves accuracy of noninvasive evaluation of cardiac volumes limiting data scatter and provides reliable clinical guidance [2]. Moreover RT-3D echo, by accurate assessment of stroke volume (SV), allows to derive a set of hemodynamic measures usually difficult or impossible to obtain with 2D echo, such as LV elastance, arterial elastance, ventricular-arterial coupling and systemic vascular resistances [3-5].

The underlying idea of the present study was to take advantage of the superiority of 3D over 2D echocardiography in assessing LV volumes to derive more accurate non invasive estimates of cardiac-vascular function $[6,7]$.

The purpose of this study was to evaluate the feasibility and time cost of RT-3D echo, as compared to standard 2D echo, in the setting of a primary care echocardiography laboratory.

We also evaluated RT3D derived cardiac and vascular hemodynamics in hypertensive and heart failure patients. In fact, RT3D-derived parameters such as left ventricular elastance or systemic vascular resistances reflect the complex interactions between the heart and its internal and external loads and are of emerging importance in the assessment and management of hypertension and heart failure [8].

\section{Study population}

The study has been conducted in 3 different primary care cardiology outpatients clinic (Echocardiography Laboratories of Savona, of Lucca, and of Barga cardiology services). All exams were performed by the same cardiologist-echocardiographer who performed both 2D and 3D echo examinations. To minimize variability the same observed, acquired and analyzed all studies. The observer had undergone a dedicated 9 month training on 3-D and the variability observed in a consecutive set of 10 studies was consistently $<10 \%$ for LV volumes. We initially considered 400 patients, referred for clinically driven Echo evaluation between May 2009 and June 2011. Sixty patients denied the consent to enter the 3D part of the study, 50 had technically difficult 2D-Echo examination; 154 had exclusion criteria conditions (such as previous myocardial infarction, valvular heart disease or age below $40 \mathrm{y}$ ). One hundred and thirty six patients were eventually included in the study. They complied with the inclusion criteria:

1. Sinus Rhythm;

2. Willingness to enter the study;

3. Technically good 2D echo study;

4. Clinical-echocardiographic diagnosis of no structural heart disease $(\mathrm{N}$, with $\mathrm{SBP} \leq 139 \mathrm{mmHg}$, diastolic blood pressure $\leq 85 \mathrm{mmHg}$, and a $\mathrm{BMI} \leq 30 \mathrm{Kg} / \mathrm{m} 2$ ), free from major coronary risk factors, including diabetes, hypercholesterolemia, and cigarette smoking;

5. Clinical-echocardiographic diagnosis of essential hypertension (HYP), previously made according to standard criteria [9]: history of long standing high blood pressure, under active treatment with ACEinhibitors (68\%), and/or diuretics (84\%), and/or ARBs (36 \%), and/or Ca-channel blockers (25\%) with $\mathrm{EF}>50 \%$;

6. Clinical-echocardiographic diagnosis of heart failure (HF): history of dyspnea on effort, under active treatment with ACE-inhibitors (86\%), and/or diuretics (78 \%), and/or ARBs (28\%), and/or $\beta$ blockers (68\%), with $\mathrm{EF}<40 \%$.

\section{Study protocol}

Following standard 2D echo examination, patients underwent RT-3D echo with measurement of raw data of LV EDV and ESV and derived assessment of [10]: LV elastance (an index of LV contractility); arterial elastance (AE) (characterizing the distal impedance of the arterial system downstream of the aortic valve); ventricular-arterial coupling (a central determinant of net cardiovascular performance); systemic vascular resistances (SVR). Blood pressure was derived from cuff sphygmomanometer and heart rate from 1- lead ECG (on echo monitor). The medical records of all included patients were reviewed in detail by one investigator to identify N, HYP and HF patients. For all patients, age, cuff blood pressure, height, weight, body mass index (BMI) and body surface area (BSA) were calculated and recorded.

Mean arterial pressure (MAP) was calculated as diastolic blood pressure + (systolic blood pressure - diastolic blood pressure/3). Mitral regurgitation and pulmonary arterial pressure were estimated from standard 2D echo. Forty four patients with no overt cardiac disease, a SBP $\leq 139 \mathrm{mmHg}$, and a $\mathrm{BMI} \leq 30 \mathrm{Kg} / \mathrm{m} 2$, constituted the $\mathrm{N}$ group. Fifty seven subjects with hypertension but no HF constituted the HTN group. Thirty five patients with a clinical diagnosis of heart failure and EF below $40 \%$ constituted the systolic $\mathrm{HF}$ group. 


\section{Methods}

\section{Two-dimensional echocardiography}

Standard 2-dimensional echocardiography was performed according to the recommendation of the European Association of Echocardiography [5] using a Philips I33 scanner equipped with a phased array S5-1 1.33.6 $\mathrm{MHz}$ probe with second harmonic capability. Left atrial dimensions (parasternal and 4 chambers view), LV end-diastolic volumes (EDV) and end-systolic volumes (ESV) were measured. Ejection fraction (EF), stroke volume (SV), and cardiac output (CO) were calculated according to standard formula [5]. The echocardiogram was considered adequate if $\geq 13$ of the maximum 16 segments were visualized in at least 1 projection.

\section{Three-dimensional echocardiography}

Real time 3-dimensional echocardiography images were recorded with a Philips I33 equipped with a X3-1 1-3 MHz matrix-phased array transducer in a $60 \times 70$ pyramid shaped volume containing the entire left ventricle. Volumetric data were obtained only from the apical window and displayed as conventional 2D apical which were digitalized with final interpretation made off -line with manual identification of chambers contours in selected image. Four cardiac cycles were stitched together to obtain LV volumes.

3D-images were obtained soon after completing the 2D study using the same echocardiographic machines with a fast switch between the 2 probes [4].

$\mathrm{BP}$ and HR were taken simultaneously during volume assessment, from cuff sphygmomanometer and from EKG, respectively.

\section{Data acquisition}

LV EDV and ESV were measured from apical four- and two-chamber view, using the biplane Simpson-method [5]. Only representative cycles with optimal endocardial visualization were measured and the average of three measurements was taken. The endocardial border was traced, excluding the papillary muscles. The frame captured at the R wave of the ECG was considered to be the end-diastolic frame, and the frame with the smallest left ventricular cavity the end systolic frame.

\section{Arterial elastance and ventricular-arterial coupling}

Ventricular arterial coupling was derived by the ratio of LV systolic elastance index (systolic pressure/end-systolic volume index) to arterial elastance (ratio of end-systolic pressure by stroke volume). Effective arterial elastance $(\mathrm{EaE})$, characterizing the distal impedance of the arterial system downstream of the aortic valve, was estimated as end-systolic pressure (ESP) divided by stroke volume (SV) and expressed as SP/ESV index $=\mathrm{mmHg} / \mathrm{mL} / \mathrm{m}^{2}$. ESP was estimated as systolic pressure times 0.9 [7].
Because stroke volume (and input impedance) varies directly with body size, arterial elastance was corrected for BSA (EaE) to better reflect differences in arterial properties with age and between the genders adjusted for differences in body size [11]. Of note ventricular-arterial coupling is ventricular elastance/arterial elastance, which can further be described as: ESP/ESV divided by ESP/ SV: the pressure terms in the numerator and the denominator cancel out, and ventricular-arterial coupling equals to stroke volume/end-systolic volume.

\section{Systemic Vascular Resistance (SVR)}

SVR were calculated according to the traditional formula:

$$
\mathrm{SVR}=80 *(\mathrm{MAP}-5) / \mathrm{CO}
$$

where 5 is an approximation of the right atrial pressure and MAP is mean arterial pressure and $\mathrm{CO}$ is Cardiac Output. Vascular resistance is a term used to define the resistance to flow that must be overcome to push blood through the circulatory system. The resistance offered by the peripheral circulation is known as the systemic vascular resistance. Vasoconstriction (i.e., decrease in blood vessel diameter) increases systemic vascular resistance, whereas vasodilatation (increase in diameter) decreases systemic vascular resistance. Units for measuring vascular resistance are dyne* $\mathrm{s} / \mathrm{cm}^{5}$.

\section{Systemic arterial compliance}

Systemic arterial compliance was calculated as SV index/systemic arterial pulse pressure; where pulse pressure $=$ SBP - DBP $[10,12]$.

\section{Statistics}

Software (SPSS 11 for Windows, SPSS, Chicago, Ill) was used for statistical analysis. The statistical analyses included descriptive statistics (frequency and percentage of categorical variables and mean and standard deviation of continuous variables). One-way ANOVA was used to compare continuous variables between groups with intergroup comparisons by Newman-Keuls test. The agreement between continuous or discrete data was tested by the Bland-Altman method and by the concordance correlation coefficient comparing the mean differences between the two methods of measurements and $95 \%$ limits of agreement as the mean difference. A p value of 0.05 was considered as statistically significant.

\section{Results}

Patients demographic and hemodynamic parameters are presented in Table 1.

Standard 2D Echo was performed in 136 (68 females) patients. Diagnostic quality images with RT-3D echo 
Table 1 Study population and hemodynamic parameters

\begin{tabular}{|c|c|c|c|}
\hline & $\mathrm{N}$ & HYP & $\mathrm{HF}$ \\
\hline N. & 44 & 57 & 35 \\
\hline Females & 32 & 22 & 14 \\
\hline $\mathrm{BSA} \mathrm{m^{2 }}$ & $1.7 \pm 0.2$ & $1.9 \pm 0.2$ & $1.9 \pm 0.2$ \\
\hline LVEF\% & $62 \pm 6$ & $63 \pm 9$ & $35 \pm 5 *$ \\
\hline LVEDV $\left(\mathrm{ml} / \mathrm{m}^{2}\right)$ & $51 \pm 14$ & $50 \pm 13$ & $83 \pm 28 *$ \\
\hline LVESV $\left(\mathrm{ml} / \mathrm{m}^{2}\right)$ & $19 \pm 5$ & $20 \pm 8$ & $56 \pm 29 *$ \\
\hline SBP $(\mathrm{mmHg})$ & $127 \pm 15$ & $147 \pm 14$ * & $126 \pm 18$ \\
\hline $\mathrm{DBP}(\mathrm{mmHg})$ & $70 \pm 9$ & $83 \pm 8^{*}$ & $78 \pm 11$ \\
\hline
\end{tabular}

${ }^{*}=\mathrm{p}<.01$ vs other groups

were obtained in 130 patients (feasibility $95 \%$ ) that were distributed as follows: no structural cardiac disease $(\mathrm{N}$, 44), hypertension without heart failure (HTN, 56), and systolic heart failure $(\mathrm{EF}<40 \%)(\mathrm{HF}, 30)$. The commonest reason for incomplete RT3D was ventricular dimension exceeding the area covered by the probe.

$\mathrm{LV}$ volumes obtained with standard echo and with RT$3 \mathrm{D}$ echo were plotted according to the Bland-Altman method. End-systolic as well end-diastolic volumes showed a significant correlation $(\mathrm{p}<0.001$, Figure $1-2)$. In particular, a mean difference of $5.6 \mathrm{ml}(95 \%$ CI $1.8-$ 9.4; $\mathrm{r}=1.52 ; \mathrm{p}=0.28)$ for ESV and $6.1 \mathrm{ml}(95 \% \mathrm{CI} 5.6$ $6.8 ; \mathrm{r}=0.21 ; \mathrm{p}=0.12$ ) for EDV was found.

\section{Additional workload associated with RT3D echo}

Standard 2D echo examination was completed in $14.8 \pm 2.2 \mathrm{~min}$. Acquisition of 3D images required an additional time of $5 \pm 0.9 \mathrm{~min}$ (range $3.5 \mathrm{~min} / 7.5 \mathrm{~min}$ ) and image analysis was completed in $10 \pm 2.8 \mathrm{~min}$ (range $6.6 \mathrm{~min}-12.8 \mathrm{~min}$ ) per patient. Therefore the completion of a RT3D echo study from imaging to analysis requires a time interval comparable to a standard 2D examination.

\section{Non-invasive hemodynamic assessment}

A reduced ventricular elastance was found in HF patients as compared to $\mathrm{N}$ and HYP (Table 2 and Figure 3). Ventricular-arterial coupling was also reduced in HF patients compared to N and HYP (Table 2 and Figure 4). Vascular elastance was significantly higher in HYP than in $\mathrm{N}$ and HF patients (Table 2 and Figure 5). HYP had the highest systemic vascular resistances (Table 2 and Figure 6).

A significant relation was found between LV elastance and EF $(r=0.73, p<0.01)$ (Figure 7, panel A) and systemic arterial pressure was moderately related to vascular elastance $(\mathrm{r}=0.54, \mathrm{p}<0.01)$ (Figure 7 , panel $\mathrm{B})$. No significant correlation was found between ventriculararterial coupling and systemic vascular resistances $(\mathrm{r}=0.04, \mathrm{p}=\mathrm{NS})$.

\section{Discussion}

The primary purpose of this study was to test the feasibility of RT3D, and to estimate the time required to complete a RT-3D examination as compared to standard echo. The main finding of this study is that RT3D Echo, thanks to recent technological advances and to new, user-friendly software [10], can be performed in most patients referred for routine echo examination, and that RT-3D echo allows the assessment of cardiac hemodynamics in a variety of clinical conditions, in a relatively easy and quick fashion, at an acceptable time cost. Of interest, diagnostic quality RT-3D images were obtained in $95 \%$ of patients with an acceptable acoustic window. The commonest reason for failed RT3D examination in this group was the presence of a markedly dilated left ventricle, exceeding the field of view of the 3D probe. Further technological advances promise to overcome this limitation.

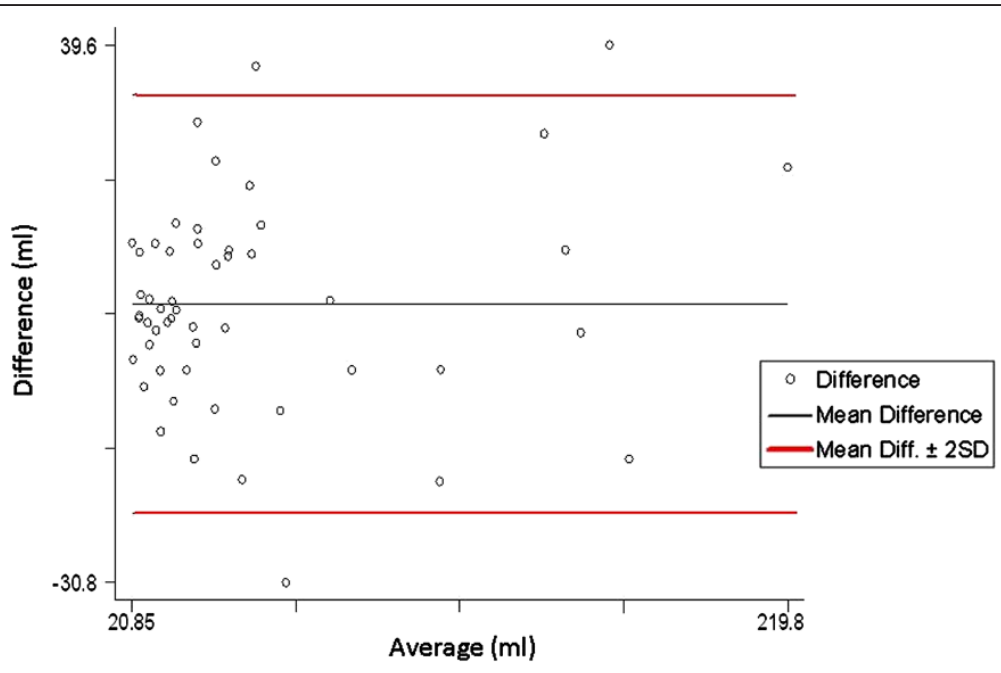

Figure 1 Bland-Altman plot for End-systolic volumes. 


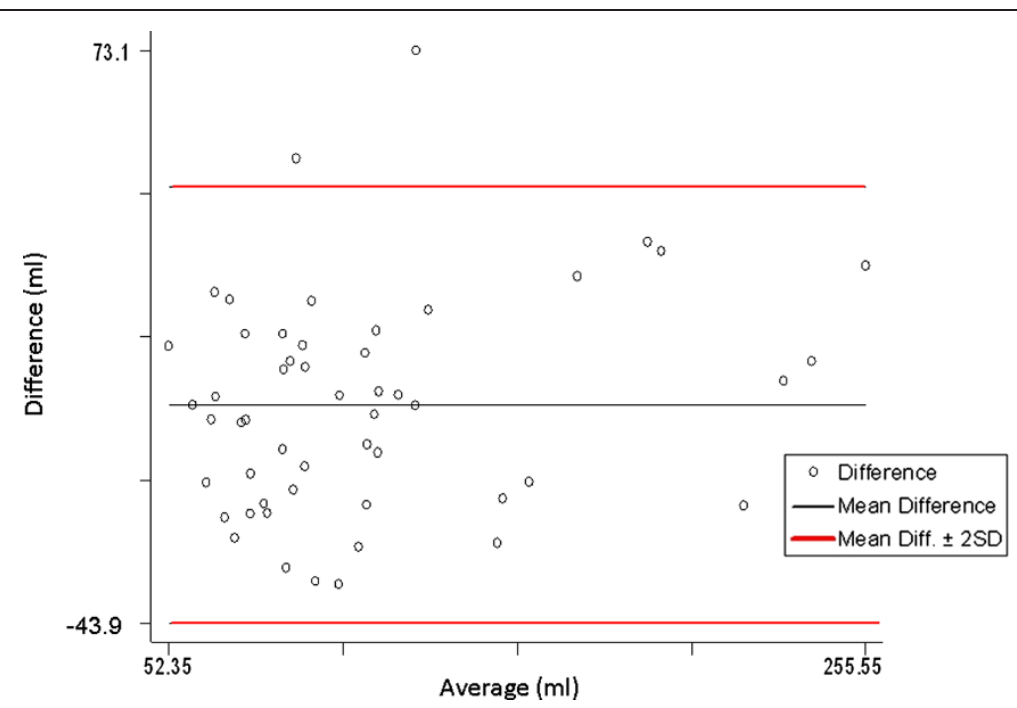

Figure 2 Bland-Altman plot for End-diastolic volumes.

Anticipated technological advances and new softwares will further shorten both acquisition time and analysis time, rendering RT-3D echo more and more attractive.

Table 2 Hemodynamic evaluation by RT3D echocardiography

\begin{tabular}{llll}
\hline & $\mathbf{N}$ & HYP & Syst HF \\
\hline LV Elastance & $3.8 \pm 1.2$ & $3.8 \pm 1.3$ & $1.7 \pm 1.5^{*}$ \\
$\mathrm{mmHg} / \mathrm{ml} / \mathrm{m}^{2}$ & & & \\
Arterial Elastance & $2.7 \pm 0.9$ & $3.3 \pm 0.9 *$ & $2.4 \pm 0.8$ \\
$\mathrm{mmHg} / \mathrm{ml} / \mathrm{m}^{2}$ & & & \\
V-A Coupling & $1.4 \pm 0.4$ & $1.2 \pm 0.4$ & $0.6 \pm 0.5 *$ \\
SVR & $1980 \pm 432$ & $2736 \pm 720 *$ & $1855 \pm 636$ \\
dyne* $/ \mathrm{cm}^{5}$ & & &
\end{tabular}

${ }^{*}=\mathrm{p}<.01$ vs other groups.

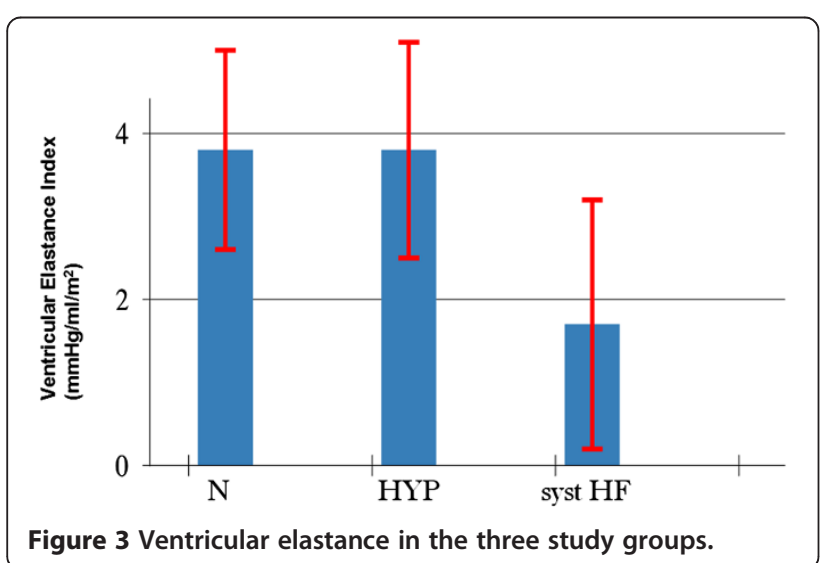

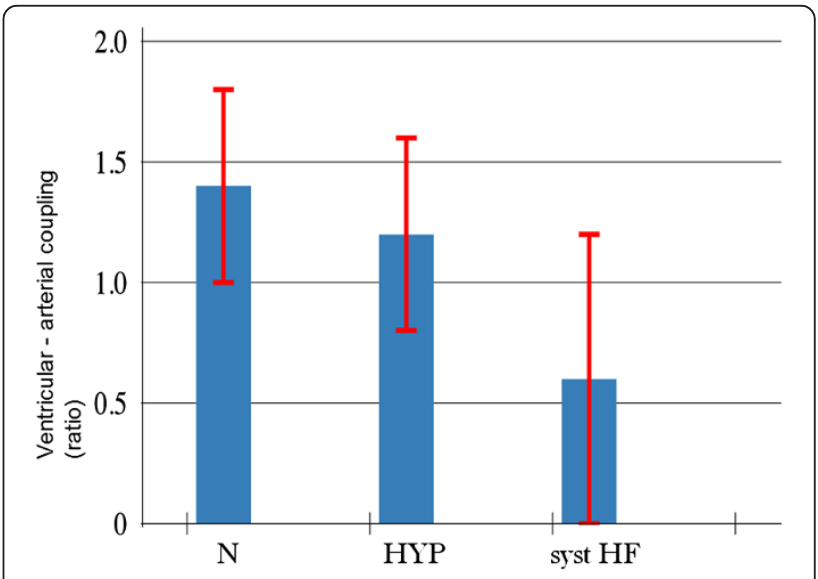

Figure 4 Ventricular-arterial coupling in the three study groups.

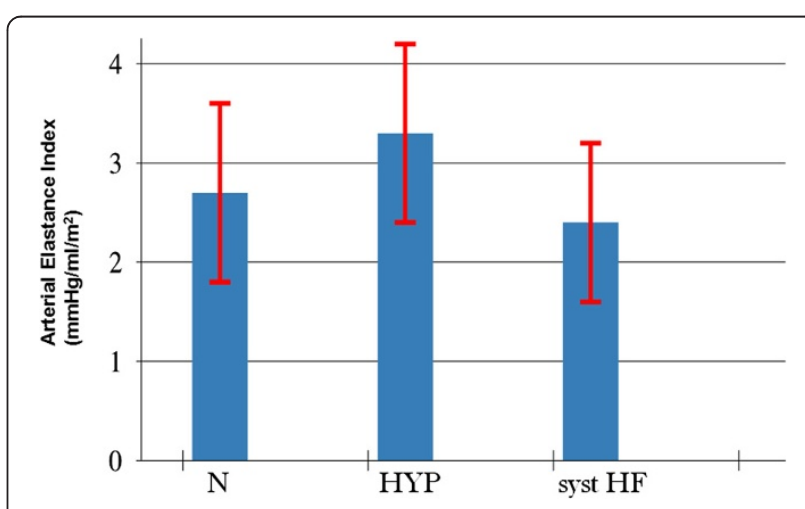

Figure 5 Arterial Elastance in the three study groups. 


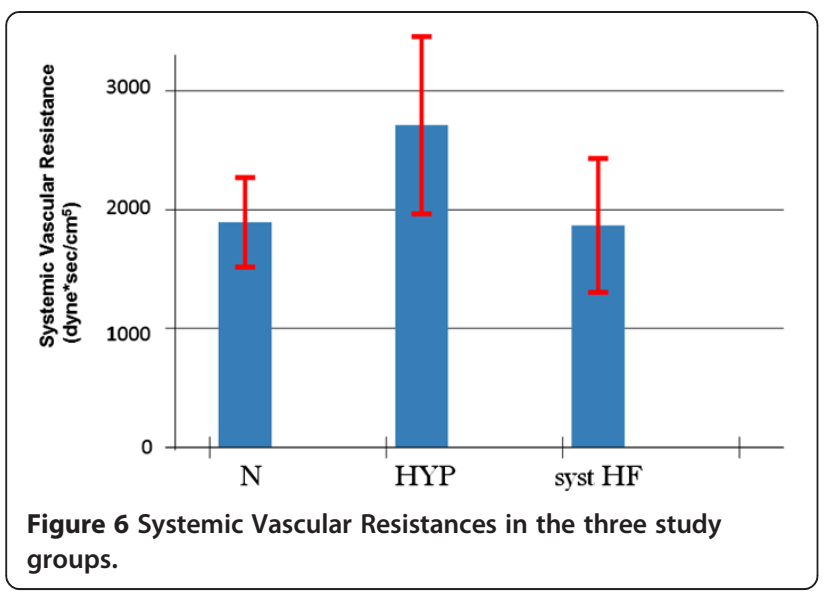

In keeping with previous studies, we found that LV elastance, vascular elastance, ventricular-arterial coupling, systemic vascular resistance, and other key hemodynamic parameters such as $\mathrm{CO}$ and SV, can be easily and quickly obtained with RT-3D echo in a number of cardiac conditions, including HYP, HF, and N patients [10-12].

3D echo makes it possible to capture the shape and function of the entire LV in a single data set. Compared with $2 \mathrm{D}$ echo, this is an advantage for LV quantification, since geometric assumptions of $\mathrm{LV}$ shape can be ignored. Moreover, 3D echo allows for manually aligning the displayed view to the true anatomical LV main axis, avoiding foreshortening and ensuing a precise identification of the LV apex.
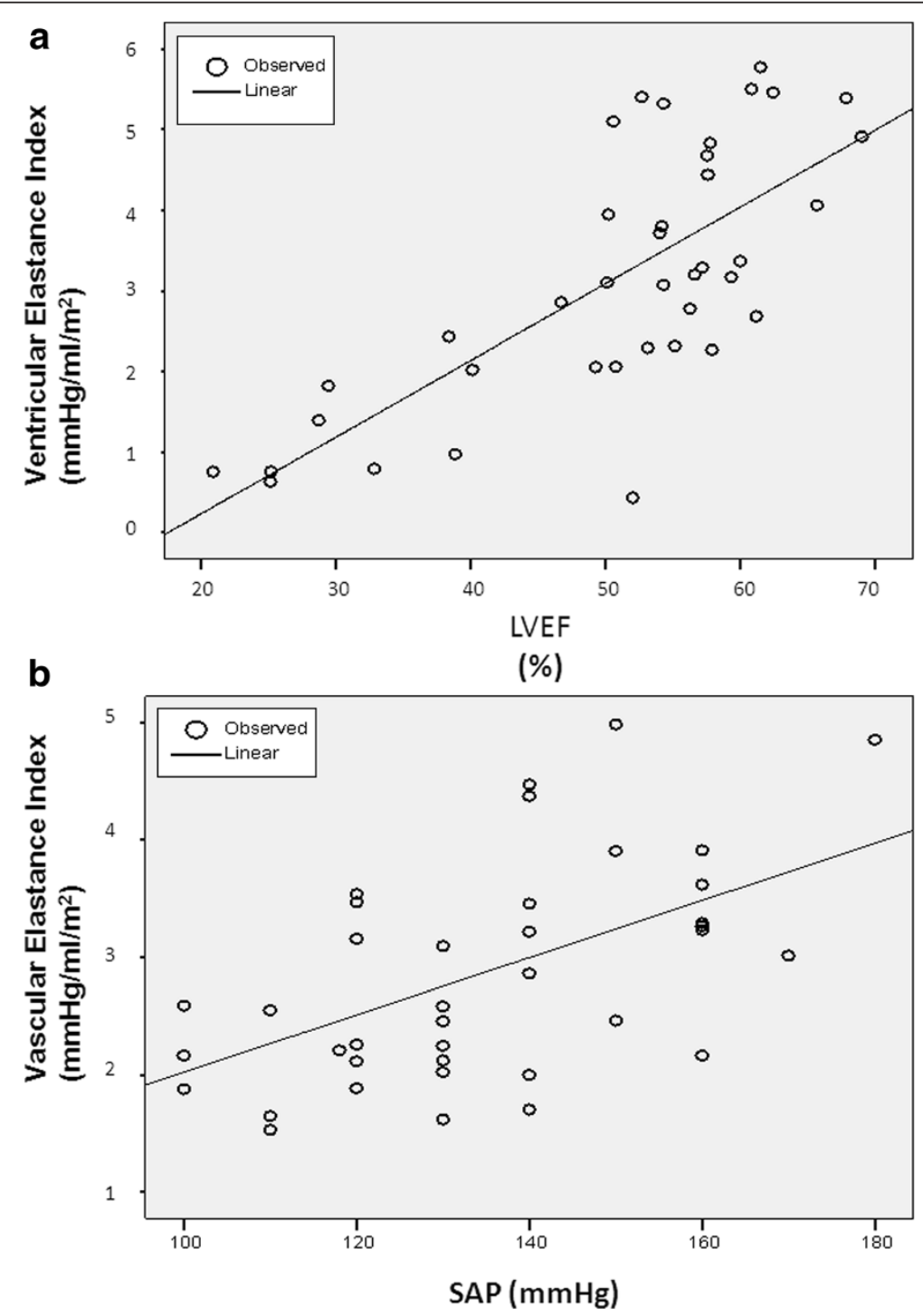

Figure 7 Ventricular elastance vs ejection fraction (Panel A) and Vascular elastance vs systolic pressure (Panel B). 
In direct comparisons, RT-3D echo has been shown to be as accurate as contrast-enhanced 2D echo in left ventricular volume measurement. In addition, LV and RV volumes by 3D Echo have been reported to compare favorably with cardiac magnetic resonance (CMR) and Gated-SPECT imaging [13-16].

Compared to cardiac MRI, the currently accepted gold standard technique for LV quantification, 3D echo provides a good agreement for assessing EF with slightly underestimation of volumes, which may be attributed to the different modality in visualization of trabeculae and valves between the two techniques [17]

\section{Limitations}

This study was not aimed to assess accuracy and reproducibility of 3D echo measurement of LV volumes, but to investigate the additional time costs of RT-3D images and its practicability

Calculation of the end-systolic pressure/volume ratio would require the measurement of LV pressure in endsystole. Because only non-invasive measurements were available, systolic cuff pressure was used as a surrogate for end-systolic pressure. This certainly introduces an approximation, however, there is a tight relationship between peak and end-systolic pressure [18].

The conceptual novelty of the employed approach is limited, since already Bombardini et al. extensively showed that this approach can be usefully applied to non invasive ultrasound at rest and during stress such as exercise, dobutamine, dipyridamole and pacing $[11,12,19]$. However, we adopted firstly $3 \mathrm{D}$ echo which may introduce a crucial step-up in the feasibility and accuracy of the method, allowing to avoid inherent inaccuracies of the 2D-approach for volume calculations.

Hemodynamic variables assessed in this study may be affected by drug therapy. ß-blockers may reduce aortic wave reflection and improve left ventricular/vascular coupling, and $68 \%$ of patients in the HF group were on ß-blockers [20]. However, this observation does not impact on our conclusions because we observed a reduced $\mathrm{V} / \mathrm{A}$ coupling in the HF group as compared to $\mathrm{N}$ and Hyp patients, so, if anything, we are underestimating the difference.

\section{Conclusion}

In this study we have shown that RT-3D can be performed in the vast majority of patients referred for echocardiographic examination at an acceptable time cost, comparable to standard 2D echo. Only patients with bad acoustic window or with markedly enlarged left ventricle may pose a difficult challenge. Reliable and detailed assessment of cardiac and systemic hemodynamics more than compensate for the time required for data acquisition and off-line analysis. Standard 2D echo will certainly remain the first line technique for LV assessment in the near future, given its large availability, its relative easiness, and the established role. However, when volumes are important and sequential testing is required, the $3 \mathrm{D}$ technique appears to be an attractive and practical alternative, offering also insight into variables of pathophysiological and potential clinical relevance, such as increased systemic vascular resistances in hypertensives and reduced left ventricular elastance in heart failure patients.

\section{Abbreviations}

AE: Arterial elastance; ARBs: Angiotensin receptor blockers; BSA: Body surface area; EaE: Effective arterial elastance; EDV: End-diastolic volume; ESP: Endsystolic pressure; ESV: End-systolic volume; HF: Heart failure; LV: Left ventricular; MAP: Mean arterial pressure; SVR: Systemic vascular resistance; SV: Stroke volume.

\section{Competing interest}

The authors declare that they have no competing interests.

\section{Author details}

${ }^{1}$ Cardiologia Asl 2 Lucca, Lucca, Italy. ${ }^{2}$ U.O. Cardiologia, Ospedale San Paolo, Savona. ${ }^{3} \mathrm{CNR}$, Institute of Clinical Physiology, Pisa, Italy. ${ }^{4} \mathrm{C} / \mathrm{o}$ Cardiology Unit, Ospedale San Francesco, Via dei Frati, 1, 55051Barga, Lucca, Italy.

\section{Authors' contributions}

MCS, designed the study, collected and interpreted the data, carried out the statistical analysis. MB, AG and PB helped to collect the data. TB, was involved in designing of the study and revision of the manuscript critically for important intellectual content. RS, was involved in designing of the study and critical revision of the manuscript. All authors read and approved the final manuscript.

Received: 2 April 2012 Accepted: 28 June 2012

Published: 28 June 2012

\section{References}

1. Bernard $Y$, Meneveau N, Boucher S, Magnin D, Anguenot T, Schiele F, Vuillemenot A, Bassand JP: Lack of agreement between left ventricular volumes and ejection fraction determined by two-dimensional echocardiography and contrast cineangiography in postinfarction patients. Echocardiography 2001, 18:113-122.

2. Lang RM, Badano LP, Tsang W, Adams DH, Agricola E, Buck T, Faletra FF, Franke A, Hung J, de Isla LP, Kamp O, Kasprzak JD, Lancellotti P, Marwick TH, McCulloch ML, Monaghan MJ, Nihoyannopoulos P, Pandian NG, Pellikka PA, Pepi M, Roberson DA, Shernan SK, Shirali GS, Sugeng L, Ten Cate FJ, Vannan MA, Zamorano JL, Zoghbi WA, American Society of Echocardiography, European Association of Echocardiography: EAE/ASE Recommendations for image acquisition and display using Three-dimensional echocardiography. J Am Soc Echocardiogr 2012, 25:3-46.

3. Nesser HJ, Mor-Avi V, Gorissen W, Weinert L, Steringer -Mascherbauer R, Niel J, Sugeng L, Lang RM: Quantification of left ventricular volumes using three-dimensional echocardiography speckle tracking: a comparison with MRI. Eur Heart J 2009, 30:1565-1573.

4. Hung J, Lang R, Flachscampf F, Shernan SK, McCulloch ML, Adams DB, Thomas J, Vannan M, Ryan T: ASE: 3 D echocardiography: a review of the current status and future directions. J Am Soc Ecocardiogr 2007, 20:213-233.

5. Lang RM, Bierig M, Devereux RB, Flachskampf FA, Foster E, Pellikka PA, Picard MH, Roman MJ, Seward J, Shanewise JS, Solomon SD, Spencer KT, Sutton MS, Stewart WJ: Chamber Quantification Writing Group; American Society of Echocardiography's Guidelines and Standards Committee; European Association of Echocardiography, Recommendations for chamber quantification: a report from the American Society of Ecocardiography's Guidelines and Standards Committee and the Chamber Quantification Writing Group developed in conjunction with 
the European Association of Echocardiography, a branch of European Society of Cardiology. J Am Soc Ecocardiogr 2005, 18:1440-1463.

6. Gayat E, Mor-Avi V, Weinert L, Yodwut C, Lang RM: Noninvasive quantification of left ventricular elastance and ventricular arterial coupling using three-dimensional echocardiography and arterial tonometry. Am J Physiol Heart Circ Physiol 2011, 301:H1916-H1923.

7. Gayat E, Mor-Avi V, Weinert L, Shah SJ, Yodwut C, Lang RM: Noninvasive estimation of left ventricular compliance using three-dimensional echocardiography. J Am Soc Echocardiogr 2012, 25:661-6.

8. Borlaug BA, Kass DA: Invasive hemodynamic assessment in heart failure. Cardiol Clin 2011, 29:269-280

9. Mancia G, De Backer G, Dominiczak A, Cifkova R, Fagard R, Germano G, Grassi G, Heagerty AM, Kjeldsen SE, Laurent S, Narkiewicz K, Ruilope L, Rynkiewicz A, Schmieder RE, Boudier HA, Zanchetti A, Vahanian A, Camm J, De Caterina R, Dean V, Dickstein K, Filippatos G, Funck-Brentano C Hellemans I, Kristensen SD, McGregor K, Sechtem U, Silber S, Tendera M, Widimsky P, Zamorano JL, Erdine S, Kiowski W, Agabiti-Rosei E, Ambrosioni E, Lindholm LH, Viigimaa M, Adamopoulos S, Agabiti-Rosei E, Ambrosioni E, Bertomeu V, Clement D, Erdine S, Farsang C, Gaita D, Lip G, Mallion JM, Manolis AJ, Nilsson PM, O'Brien E, Ponikowski P, Redon J, Ruschitzka F, Tamargo J, van Zwieten P, Waeber B, Williams B: 2007 Guidelines for the management of arterial hypertension: The Task Force for the Management of Arterial Hypertension of the European Society of Hypertension (ESH) and of the European Society of Cardiology (ESC). Eur Heart J 2007, 28:1462-1536.

10. Bombardini T, Cini D, Arpesella G, Picano E: WEB downloadable software for training cardiovascular hemodynamics in the (3-D) stress echo lab. Cardiovasc Ultrasound 2010, 8:48.

11. Grosu A, Bombardini T, Senni M, Duino V, Gori M, Picano E: End-systolic pressure/volume relationship during dobutamine stress echo: a prognostically useful non-invasive index of left ventricular contractility. Eur Heart J 2005, 26:2404-2412.

12. Bombardini T, Gemignani V, Bianchini E, Venneri L, Petersen C, Pasanisi E, Pratali L, Pianelli M, Faita F, Giannoni M, Picano E: Cardiac reflections and natural vibrations: Force- frequecy relation recording system in the stress echo lab. Cardiovasc Ultrasound 2007, 5:42.

13. Jenkins C, Moir S, Chan J, Rakhit D, Haluska B, Marwick TH: Left ventricular volume measurement with echocardiography: a comparison of left ventricular opacification, three-dimensional echocardiography, or both with magnetic resonance imaging. Eur Heart J 2009, 30:98-106.

14. Tighe DA, Rosetti M, Vinch CS, Chandok D, Muldoon D, Wiggin B, Dahlberg ST, Aurigemma GP: Influence of image quality on the accuracy of real time three-dimensional echocardiography to measure left ventricular volumes in unselected patients: a comparison with gated-SPECT imaging. Echocardiography 2007, 24:1073-1080.

15. Chan J, Jenkins C, Khafagi F, Du L, Marwick TH: What is the optimal clinical technique for measurement of Left Ventricular volume after myocardial infarction: a comparative study of 3-Dimensional echocardiography, Single Photon Emission Computer Tomography, and cardiac Magnetic Resonance Imaging. J Am Soc Echoacrdiogr 2006, 19:192-201.

16. Gutierrez-Chico JL, Zamorano JL, Prieto-Moriche E, Hernandez-Antolin RA, Bravo-Amaro M, Perez de Isla L, Sanmartin-Fernandez M, Baz-Alonso JA, Iniguez-Romo A: Real-time-three-dimensional echocardiography in aortic stenosis: a novel, simple, and reliable method to improve accuracy in area calculation. Eur Heart J 2008, 29:1296-1306.

17. Niemann PS, Pinho L, Balbach T, Galuschky C, Blankenhagen M, Silberbach M, Broberg C, Jerosch-Herold M, Sahn DJ: Anatomically oriented right ventricular volume measurements with dynamic three-dimensional echocardiography validated by 3-Tesla magnetic resonance imaging. J Am Coll Cardiol 2007, 50:1668-1676.

18. Slutsky R, Karliner J, Gerber K, Battler A, Froelicher V, Gregoratos G, Peterson K, Ashburn W: Peak systolic blood pressure/end-systolic volume ratio: assessment at rest and during exercise in normal subjects and patients with coronary heart disease. Am J Cardiol 1980, 46:813-820.

19. Bombardini T, Agrusta M, Natsvlishvili N, Solimene F, Pap R, Coltorti F, Varga A, Mottola G, Picano E: Noninvasive assessment of left ventricular contractility by pacemaker stress echocardiography. Eur J Heart Fail 2005, 7:173-181.

20. Shah NK, Smith SM, Nichols WW, Lo MC, Ashfaq U, Satish P, Johnson JA, Epstein BJ: Carvedilol reduces aortic valve reflection and improves left ventricular/vascular coupling: a comparison with atenolol (CENTRAL Study). J Clin Hypertens 2011, 13:917-924.

doi:10.1186/1476-7120-10-27

Cite this article as: Scali et al:: Real Time 3D echocardiography (RT3D)

for assessment of ventricular and vascular function in hypertensive and heart failure patients. Cardiovascular Ultrasound 2012 10:27.

\section{Submit your next manuscript to BioMed Central and take full advantage of:}

- Convenient online submission

- Thorough peer review

- No space constraints or color figure charges

- Immediate publication on acceptance

- Inclusion in PubMed, CAS, Scopus and Google Scholar

- Research which is freely available for redistribution

Submit your manuscript at www.biomedcentral.com/submit
() Biomed Central 